\title{
Drug users' failure to modify alcohol consumption in response to hepatitis $\mathrm{C}$
}

\author{
Angela Noonan, Paul Kavanagh, Brion Sweeney
}

Ir J Psych Med 2009; 26(1): 27-31

\begin{abstract}
Objective: To measure (a) the prevalence of problem drinking in a population of methadone-treated drug users, (b) independent associations with problem drinking, (c) the effect of hepatitis $C$ status on drinking behaviour, (d) the knowledge of drug users of their hepatitis $C$ status and their perception of their drinking behaviour and (e) the attitude of drug users to the effect of alcohol on hepatitis $C$ virus ( $\mathrm{HCV}$ ) related disease.

Method: A cross sectional survey of $\mathbf{1 3 0}$ drug users in treatment at the National Drug Treatment Centre, Dublin was carried out. A questionnaire incorporated the Alcohol Use Disorders Identification Test (AUDIT), and data were collected on sociodemographics, drug use history, perceived HCV status and drinking behaviour, and attitudes to the impact of drinking on HCV related disease. Hepatitis serology and drug urine data were collected from clinical records.

Results: The prevalence of problem drinking was $41 \%$ (95\% Cl 33-51\%). Unstable accommodation, older age, male gender and longer duration of heroin use were independent associations with being a problem drinker. There was no significant difference in the prevalence of problem drinking across HCV status. Knowledge of HCV status was accurate, however $35 \%$ of those identified as AUDIT cases failed to recognise their problem drinking.

Conclusion: HCV infection among Irish drug users is compounded by a high prevalence of problem drinking with drug users failing to modify their drinking in response. Incorrect perception of problem drinking status could be a barrier to addressing this potentially remediable risk factor.
\end{abstract}

Key words: HCV infection; Alcohol; Methadone; Problem drinking.

\section{Introduction}

In common with many other countries, in Ireland hepatitis $\mathrm{C}$ virus ( $\mathrm{HCV}$ ) infection is endemic among the drug using population. For drug users in contact with treatment services,

*Angela Noonan, MSc, MRCPsych, Senior Registrar, Central Mental Hospital, Dundrum, Dublin 14, Ireland.

Email: angenoonan@eircom.net

Paul Kavanagh, MICP, Specialist Registrar in Public Health Medicine, Health Information Unit, Health Intelligence, Population Health Directorate, Dr. Steevens Hospital, Dublin 8, Ireland.

Brion Sweeney, MRCPsych, Consultant Psychiatrist, Drug

Treatment Centre Board, Trinity Court, Pearse St, Dublin 2, Ireland. ${ }^{*}$ Correspondence

SUBMITTED: MAY 18, 2008. ACCEPTED: JULY 29, 2008. measures of the prevalence of HCV anti-bodies between $61.8 \%$ and $84 \%$ have been reported,,$^{1,2}$ and the incidence has been estimated to be $66 / 100$ person years at risk. ${ }^{3}$ Natural history studies of $\mathrm{HCV}$ infection have estimated progression to cirrhosis in up to $24 \%$ of HCV infected patients after 20 years. ${ }^{4}$ Approximately 170 million people are infected with HCV worldwide, comprising approximately $3 \%$ of the global population, ${ }^{5}$ and currently, HCV is the most common cause of chronic liver disease and liver transplantation in the USA, Australia and most of Europe. ${ }^{6-8}$

Even conservative predictions estimate that the burden of $\mathrm{HCV}$ related disease will pose a major challenge for most health systems in the future. For example, based on age-specific prevalence data from the National Health and Nutrition Examination III (NHANES III), it has been estimated that in the period $2010-2019$, HCV may lead to 720,700 person years of decompensated cirrhosis and hepatocellular carcinoma, with a loss of 1.83 million years of life in those under 65 years of age and with a societal cost of $\$ 21.3$ million and $\$ 54.2$ million respectively. ${ }^{9}$ Similar estimates have been produced in France. ${ }^{10}$

In Ireland, extrapolating from a cohort of HCV PCR positive drug users, Kavanagh et al estimated that approximately 35 cases of hepatocellular carcinoma, 60 cases of hepatic decompensation and 50 liver related deaths could be expected to occur annually among the Irish opiate dependent population. ${ }^{11}$

Alcohol has been clearly shown to have an independent and multiplicative effect on the progression of $\mathrm{HCV}$ related liver disease, ${ }^{12}$ even in moderate amounts. ${ }^{13}$ Indeed, it has not been established that there is a 'safe' lower limit in those who are infected with HCV. To date there have been no studies published on the drinking response of the Irish drug using population to HCV infection.

The ROSIE (Research Outcome Study in Ireland) study examined one year outcomes of a cohort of opiate users in treatment. At one year participants reported reductions in the use of unprescribed methadone and benzodiazepines, heroin, cocaine and crack cocaine but there was no significant change in the proportion using alcohol, mean alcohol consumption or mean number of days on which alcohol was consumed. ${ }^{14}$ A study conducted on a different cohort to the current study, of drug users in treatment in Dublin, used the Alcohol Dependence Scale and found a 56\% prevalence rate of alcohol dependence. ${ }^{15}$

Comparison of international data is difficult due to the differing criteria used to evaluate drinking behaviour, however published studies indicate that problem drinking is a common co-morbidity in drug users. Problem drinking prevalence between $12 \%$ and $42 \%$ was reported in two American studies carried out in the 1970s. ${ }^{16,17}$ The Tri-State Ethnographic 


\begin{tabular}{|c|c|c|c|c|}
\hline \multirow[b]{2}{*}{ Characteristic } & \multicolumn{3}{|c|}{ AUDIT } & \multirow[b]{2}{*}{ p-valuet } \\
\hline & Total n (\%) & Case n (\%) & Non-Case n (\%) & \\
\hline \multicolumn{5}{|l|}{ Gender } \\
\hline Male & $67(65.0 \%)$ & $35(81.4 \%)$ & $32(53.3 \%)$ & \multirow[t]{2}{*}{0.0032} \\
\hline Female & $36(35.0 \%)$ & $8(18.4 \%)$ & $28(46.7 \%)$ & \\
\hline Age (years)* & $28(23-32)$ & $33(25-38)$ & $27(23-29)$ & $<0.0001$ \\
\hline Age first drug use (years) ${ }^{*}$ & $14(13-16)$ & $14(12-16)$ & $15(13-16)$ & 0.41 \\
\hline Age first main drug use (years)* & $17(15-22)$ & $16(15-19)$ & $17(15-22)$ & 0.14 \\
\hline Years main drug use* & $9(6-15)$ & $16(8-20)$ & $8(5-10)$ & $<0.0001$ \\
\hline Years any drug use* & $12(9-18)$ & $19(11-23)$ & $11(8-15)$ & $<0.0001$ \\
\hline Age left school (years)* & $15(14-16)$ & $14(13-16)$ & $15(14-16)$ & 0.02 \\
\hline \multicolumn{5}{|l|}{ Accommodation } \\
\hline Roofless sleeper & $9(8.7 \%)$ & $7(16.3 \%)$ & $2(3.3 \%)$ & \multirow[t]{3}{*}{0.04} \\
\hline Stable & $75(72.9 \%)$ & $27(62.3 \%)$ & $48(80.0 \%)$ & \\
\hline Unstable & $19(18.4 \%)$ & $9(20.9 \%)$ & $10(16.7 \%)$ & \\
\hline \multicolumn{5}{|l|}{ No. of drugs used } \\
\hline 1 & $1(1.0 \%)$ & $0(0 \%)$ & $1(1.7 \%)$ & \multirow[t]{5}{*}{0.20} \\
\hline 2 & $3(2.9 \%)$ & $3(7.0 \%)$ & $0(0.0 \%)$ & \\
\hline 3 & $5(4.8 \%)$ & $3(7.0 \%)$ & $2(3.3 \%)$ & \\
\hline 4 & $25(24.3 \%)$ & $9(21.0 \%)$ & $16(26.7 \%)$ & \\
\hline$>4$ & $69(67.0 \%)$ & $28(65.0 \%)$ & $41(68.3 \%)$ & \\
\hline
\end{tabular}

Project subsequently reported a prevalence of $16 \%$ of 'abusive pattern drinkers.' ${ }^{18}$ In the UK $39.1 \%$ of clients undergoing methadone maintenance were reported to have 'actual or potential drinking problems' measured by the self-administered alcohol screening test (mSAAST). ${ }^{19}$ Another UK study found that $41 \%$ of a sample of clients receiving methadone maintenance met DSM IV criteria for alcohol dependence. ${ }^{20}$ A review of alcohol abuse among people on methadone, by Ottomanelli, found that rates ranged from $13-25 \% .{ }^{21}$

Given that alcohol has a detrimental effect on the health of those with HCV infection, their drinking behaviour and its determinants have an important impact on their HCV-related prognosis. Clinicians involved in the treatment of those with $\mathrm{HCV}$ infection would be keen that those positive for HCV would modify their alcohol intake. In the UK McCusker examined the influence of HCV status on alcohol consumption in opiate users in treatment. ${ }^{22}$ It was found that perceived HCV positive status had some impact on drinking behaviour with fewer HCV positive than HCV negative clients consuming any alcohol in the previous year and more HCV positive clients reducing their consumption in the year after diagnosis.

In order to make a decision to modify drinking, drug users must be armed with accurate information regarding their HCV status. Though they may be aware of the risks of infection associated with their drug use they may not be as certain of their own status. Best et al reported that $13.3 \%$ of opiate users in treatment incorrectly ascertained their HCV status and $8.9 \%$ were unaware of their status. ${ }^{23}$

This study aimed to measure the prevalence of problem drinking, defined as an AUDIT score of eight or more in an Irish, opiate dependent sample receiving methadone maintenance. Awareness of HCV status and the impact of alcohol consumption on HCV related liver disease were also evaluated.

\section{Methods}

The sampling frame was clients from one of the three sectors attending the National Drug Treatment Centre. This is the longest established and largest drug treatment service in Ireland and is located in the city centre in Dublin. All current clients of the sector in the period September to December 2002 were verbally invited to participate. All participants were receiving oral methadone maintenance treatment.

A questionnaire was designed incorporating the AUDIT questionnaire, perceived HCV status, perceived drinking behaviour and knowledge of the interaction of alcohol with $\mathrm{HCV}$ liver disease. From clinical records most recent HCV, HIV and hepatitis B serology was obtained, and a measure of polydrug misuse was constructed by counting the number of drug varieties used in the previous year based on urine drug screening.

Clients were also questioned about the age at which they first used any drug, the age at which they first used opiates, the age they left school and their current accommodation status. Accommodation status was classified as roofless (ie. sleeping outdoors), unstable (ie. sleeping indoors, but no continued tenure over the last month) or stable (ie. sleeping indoors with continued tenure for at least one month).

Participants were asked to respond to the following statements. (a) 'Alcohol may worsen HCV related liver disease' and (b) 'Reducing alcohol consumption can help HCV related liver disease'. Without prompting, respondents were asked to 
Table 2: Logistic regression model to determine independent associations with being identified as a problem drinker

\begin{tabular}{|c|c|c|c|}
\hline Characteristic & $\begin{array}{l}\text { AUDIT } \\
\text { n (\%) }\end{array}$ & $\begin{array}{c}\text { OR } \\
(95 \% \text { CI) }\end{array}$ & p-value \\
\hline \multicolumn{4}{|l|}{ Gender } \\
\hline Female & $8(22.2 \%)$ & 1 & \\
\hline Male & $35(53.3 \%)$ & $\begin{array}{c}3.9 \\
(1.4-12.1)\end{array}$ & 0.01 \\
\hline \multicolumn{4}{|l|}{ Accommodation } \\
\hline Stable & $27(36.6 \%)$ & 1 & \\
\hline Other than stable & $16(57.1 \%)$ & $\begin{array}{c}6.1 \\
(1.9-23.0)\end{array}$ & 0.005 \\
\hline \multicolumn{4}{|l|}{ Age (years) } \\
\hline$<29$ & $12(22.6 \%)$ & 1 & \\
\hline$\geq 29$ & $29(63.0 \%)$ & $\begin{array}{c}4.3 \\
(1.1-17.4)\end{array}$ & 0.03 \\
\hline \multicolumn{4}{|c|}{ Main drug use (years) } \\
\hline$<10$ & $12(22.6 \%)$ & 1 & \\
\hline$\geq 10$ & $31(62.0 \%)$ & $\begin{array}{c}4.9 \\
(1.2-22.9)\end{array}$ & 0.03 \\
\hline \multicolumn{4}{|c|}{ Any drug use (years) } \\
\hline$<12$ & $11(25.6 \%)$ & 1 & \\
\hline$\geq 12$ & $32(53.3 \%)$ & $\begin{array}{c}0.6 \\
(0.2-2.5)\end{array}$ & 0.52 \\
\hline \multicolumn{4}{|c|}{ Age left school (years) } \\
\hline$<15$ & $24(52.1 \%)$ & 1 & \\
\hline$\geq 15$ & $19(33.3 \%)$ & $\begin{array}{c}0.8 \\
(0.3-2.3)\end{array}$ & 0.70 \\
\hline
\end{tabular}

self-report their HCV and problem drinker status; this report was collected prior to application of the AUDIT tool. The same investigator (AN) interviewed all participants.

The Alcohol Use Disorders Identification Test (AUDIT) was used to screen for problem drinking. An AUDIT score of eight or more was used to define a case. The AUDIT was developed from a six-country WHO collaborative project as a screening instrument for hazardous and harmful alcohol consumption. Eight is taken as the cut off point, as during the development of the AUDIT questionnaire, $92 \%$ of those diagnosed as having hazardous or harmful alcohol use, had a score of eight or more, and $94 \%$ of those with non-hazardous consumption had a score of less than eight. ${ }^{24}$ The AUDIT has been validated for use in a drug dependent population. ${ }^{25}$

Data were analysed using the Chi-squared and Kruskall Wallis tests. Using a reverse elimination strategy beginning with all significant $(p<0.05)$ associations on bivariate analysis, logistic regression was carried out to determine independent associations with problem drinking.

\section{Results}

Of the 130 clients in the study population, 103 (79\%) agreed to participate in the study. The sample consisted of 67 (65\%) men and 36 (35\%) women. The median age was 28 years. Table 1 presents the distribution of sociodemographic, personal history and drug use history characteristics across the group.

Forty-three clients were identified as audit cases indicating
Table 3: The distribution of virological results across the sample stratified by AUDIT case status

Audit

$\begin{array}{lcccc}\text { Characteristic } & \begin{array}{c}\text { Total } \\ \mathbf{n}(\%)\end{array} & \begin{array}{c}\text { Case } \\ \mathbf{n}(\%)\end{array} & \begin{array}{c}\text { Non-Case } \\ \mathbf{n}(\%)\end{array} & \text { p-valuet } \\ \text { HCV Ab } & & & & \\ \text { Negative } & 16(15.6) & 6(13.9) & 10(16.6) & 0.64 \\ \text { Positive } & 84(81.6) & 35(81.4) & 49(81.7) & \\ \text { Untested } & 3(2.8) & 2(4.7) & 1(1.7) & \\ \text { HCV PCR } & & & & \\ \text { Not applicable } & 16(15.6) & 6(13.9) & 10(16.6) & 0.57 \\ \text { Negative } & 4(3.9) & 1(2.3) & 3(5.0) & \\ \text { Positive } & 16(15.6) & 9(20.9) & 7(11.7) & \\ \text { Untested } & 67(65.0) & 27(62.8) & 40(66.7) & \\ \text { HBsAg } & & & & \\ \text { Negative } & 92(89.3) & 37(86.0) & 55(91.7) & 0.66 \\ \text { Positive } & 9(8.7) & 5(11.6) & 4(6.7) & \\ \text { Untested } & 2(1.9) & 1(2.3) & 1(1.7) & \\ \text { HIV } & & & & \\ \text { Negative } & 84(81.6) & 33(76.7) & 51(85.0) & 0.37 \\ \text { Positive } & 12(11.7) & 5(11.6) & 7(11.7) & \\ \text { Refused } & 1(1.0) & 1(2.3) & 2(3.3) \\ \text { Untested } & 6(5.8) & 4(9.3) & \\ \text { ttest characteristic across AUDIT status } & & \\ \end{array}$

a problem drinking prevalence in the population of $41 \%$ (95\% Cl 33-51\%). Bivariate analysis was used to identify those characteristics that varied significantly across problem drinker status (Table 1).

Male gender, older age, longer duration of drug use and being in accommodation that was not stable, were all significant and independent associations with the likelihood of being a problem drinker (Table 2).

Eighty-four participants ( $82 \%$ of those surveyed), were $\mathrm{HCV}$ antibody positive. The prevalence of HCV antibodies was not significantly different across problem drinker status (81.4\% for problem drinkers versus $81.7 \%$ for non-problem drinkers, $\mathrm{p}=0.64)$. Most of those who were HCV positive had no available HCV PCR test results. (Another study of Irish drug users in treatment found the prevalence of HCV PCR to be 55.7\%. ${ }^{11}$ ) Table 3 presents these results along with the distribution of other viral markers across the study group.

Most of the study participants had accurate self-reported HCV status; $99 \%$ of those who reported their HCV status as negative were correct when compared with their most recent laboratory records. However, the study group did not perform well in correctly self-reporting their problem drinker status. Thirty clients regarded their drinking as problematic and 28 (93\%) of these were AUDIT cases. Seventy-three clients believed they were not problem drinkers but 15 (21\%) were AUDIT cases. This means that $35 \%$ of those identified by the AUDIT tool as having problem drinking did not recognise their drinking as such.

Finally, participants were asked two simple questions to measure their beliefs about the effect of alcohol on HCV disease progression. Most participants agreed that alcohol had a negative effect on disease progression and agreed 
that reducing alcohol could be beneficial. Of the participants $101(98 \%)$ agreed that 'alcohol may worsen HCV related liver disease' and 94 (92\%) agreed that 'reducing alcohol consumption may help HCV related liver disease'.

\section{Discussion}

Given its impact on HCV-related disease progression, moderating or eliminating alcohol consumption is a potentially health-promoting response to a diagnosis of HCV infection. McCusker found that perceived HCV positive status had some influence on alcohol consumption among opiate users in treatment. ${ }^{22}$ The prevalence of HCV infection in our study population was high (82\%), as was the level of problem drinking $(41 \%)$.

It is worrying that the prevalence of HCV infection was not lower in the problem drinkers identified in the study population as this suggests that these drug users have not adopted healthier drinking behaviours in response to their infection. There is high awareness of the negative interaction between alcohol and hepatitis $C$ so further education in this area is unlikely to affect behaviour.

Internationally, excessive alcohol use is recognised as a significant co-morbidity for opiate addiction in treatment, ${ }^{19,20,24,26}$ with prevalence recorded at between $30 \%$ and $50 \%$. A significant finding in this study was that $35 \%$ of those who were AUDIT cases failed to identify themselves as problem drinkers. This is an area of possible intervention. Educational advice may not prove effective, however motivational interviewing is an alternative approach.

Motivational interviewing is a well studied method of counselling, developed by Miller and Rollinick. ${ }^{27}$ It involves helping people recognise and address problems, especially those who are reluctant to change and are ambivalent about changing. Some of the principles of motivational interviewing include the expression of empathy, the development of discrepancy between current behaviour and goals and involving the client actively in the process of problem solving. It has been found to be effective as a brief intervention for excessive drinking. ${ }^{28}$ It has been found to be superior to traditional advice giving in the treatment of a broad range of diseases and behavioural problems. ${ }^{29}$

Motivational interviewing has been found to reduce alcohol use among injection drug users with drinking problems. ${ }^{30}$ According to the Mesa Grande project, which reviews clinical trials for the treatment of alcohol disorders, the least supported interventions are those designed to foster insight, educate or confront. ${ }^{31}$

\section{Conclusion}

The independent associations with problem drinking of older age, longer duration of drug use, unstable accommodation and male gender are not necessarily causal and some may even be effects, but are still areas of possible intervention. Clinical assessment of drug users should include an alcohol use history as decreased awareness can reduce harm prevention behaviour on the part, both of the drug user and professional.

Ideally primary prevention strategies would successfully prevent people beginning drug use. This remains largely aspirational. Secondary prevention strategies should intervene to prevent drug users progressing to injection drug use and, if injecting, to prevent sharing injecting equipment. Despite secondary prevention strategies HCV infection continues to spread. ${ }^{3}$ Therefore programmes for HCV control in the drug using population need to consider tertiary prevention strategies which aim to ameliorate risk factors, such as alcohol misuse, to reduce disease progression and to improve access to effective treatment for infection.

According to a report produced in 2006, Ireland has the highest proportion of income spend on alcohol and the highest rate of binge drinking in the European Union. ${ }^{33}$ The SLÁN Survey of Lifestyles and Nutrition in Ireland in 2003, and more recently in 2007 , identified $13 \%$ and $8 \%$ of respondents respectively as drinking more than the recommended weekly limit. ${ }^{34,35}$ A paper on the psychological health and wellbeing of young Irish adults whose average age was 21 , found that $22 \%$ had a likely diagnosis of alcohol dependence yet none of the participants in this study classified themselves as heavy drinkers and $55 \%$ regarded themselves as moderate drinkers. ${ }^{36}$

The Alcohol Aware Practice Pilot was the first national study on alcohol in primary care. ${ }^{37}$ It found that $16 \%$ of the study population had hazardous drinking and 3\% had harmful drinking, based on AUDIT scores.

The problem drinking of those positive for HCV must be considered in the wider societal context. The high level of alcohol consumption in Ireland in general, makes it even more challenging to target this high risk group, however, as problem drinking is a potentially remediable factor for $\mathrm{HCV}$ progression it is a worthwhile undertaking.

\section{Declaration of Interest: None}

References

1. Smyth BP, Keenan E, O'Connor, JJ. Blood borne viral infection in Irish injecting drug users. Addiction 1998; 93: 1649-1656.

2. Smyth R, Keenan E, Dorman A, O'Connor JJ. Hepatitis $\mathrm{C}$ among drug users attending the National Dug Treatment Centre. Ir J Med Science 1995; 164: 267-268.

3. Smyth BP, O'Connor JJ, Barry J, Keenan E. Retrospective cohort study examining incidence of HIV and hepatitis C infection among injecting drug users in Dublin. J Epidemiol Comm Health 2003; 57: 310-311.

4. Freeman AJ, Dore GJ, Law MJ et al. Estimating progression to cirrhosis in chronic hepatitis C infection. Hepatology 2001; 34: 809-816.

5. National Institutes of Health Consensus Development Conference Statement: Management of hepatitis C. Gastroenterology 2002; 123(6): 2082-2099.

6. Wasley A, Alter MJ. Epidemiology of hepatitis C: geographic differences and temporal trends. Semin Liver Dis 2000; 20(1): 1-16.

7. Alter MJ. The epidemiology of acute and chronic hepatitis C. Clin Liver Dis 1997; 7. Alter MJ. The
1(3): 559-68.

8. Charlton M. Hepatitis C infection in liver transplantation. Am J Transplant 2001; 1(3): 197-203.

9. Wong JB, McQuillan GM, McHutchinson JG, Poynard T. Estimating future hepatitis C morbidity, mortality and costs in the United States. Am J Public Health 2000; 90: 1596-1601.

10. Deuffic S, Buffat L, Poynard T, Valleron AJ. Modelling the hepatitis $C$ epidemic in France. Hepatology 1999; 31: 1014-1018.

11. Kavanagh P, Moloney J, Quinn C, O'Kelly E, McCormick PA. High morbidity expected from cirrhosis in injecting drug users. Ir Med J 2003; 96(10): 303-305.

12. Corrao G, Arico $S$. Independent and combined action of hepatitis $C$ infection and alcohol consumption on the risk of symptomatic liver disease. Hepatology 1998; 27: 914-919.

13. Westin J, Lagging LM, Spak F el al. Moderate alcohol intake increases fibrosis progression in untreated patients with hepatitis $C$ virus infection. J Viral Hepatology 2002; 9: 235-41

14. Cox G, Comiskey C, Kelly P. ROSIE Findings 4: Summary of 1-year outcomes: methadone modality. Dublin: National Advisory Committee on Drugs 2007.

15. MacManus E, Fitzpatrick C. Alcohol dependence and mood state in a population receiving methadone maintenance treatment. Ir J Psych Med 2007; 24(1): 19-22.

16. Gelb AM, Richman BL, Peyser NP. Alcohol use in methadone maintenance clinics. Am J Drug Alcohol Abuse 1979; 6(3): 367-373.

17. Green J, Jaffe JH, Carlisi JA, Zaks A. Alcohol use in the opiate use cycle of the heroin addict. Int J Addiction 1978; 13(7): 1021-1033.

18. Hunt DE, Strug DL, Goldsmith DS, Lipton DS, Robertson K, Truitt L. Alcohol use and abuse: heavy drinking among methadone clients. Am J Drug Alcohol Abuse 1986; 12(1-2): 147-164.

19. Stastny $D$, Potter M. Alcohol abuse by patients undergoing methadone treatment programmes. Br J Addict 1991; 86(3): 307-310.

20. Hillebrand J, Marsden J, Finch E, Strang J. Excessive alcohol consumption and drinking expectations among clients in methadone maintenance. J Subst Abuse Treat 
$2001 ; 21$ (3): 155-160.

21. Ottomanelli G. Methadone patients and alcohol abuse. J Subst Abuse Treat 1999; 16(2): 113-121.

22. McCusker M. Influence of hepatitis $C$ status on alcohol consumption in opiate users in treatment. Addiction 2001; 96: 1007-1014.

23. Best D, Noble A, Finch E, Gossop M, Sidwell C, Strang J. Accuracy of perceptions of hepatitis $B$ and $C$ status: cross sectional investigation of opiate addicts in treatment. BMJ 1999; 319: 290-291.

24. Saunders JB, Aasland OG, Babor TF, de la Fuente JR, Grant M. Development of the alcohol use disorders identification test (AUDIT): WHO collaborative project on early detection of persons with harmful alcohol consumption. II. Addiction 1993; 88(6): 791-804.

25. Skipsey K, Burleson JA, Kranzler HR. Utility of the AUDIT for identification of hazardous or harmful drinking in drug-dependent patients. Drug Alcohol Depend 1997; 45(3): 157-163

26. Gossop M, Marsden J, Stewart D et al. Substance use, health and social problems of service users at 54 drug treatment agencies - intake data from the National Treatment Outcome Research Study. Br J Psychiatry 1998; 173: 166-171.

27. Miller WR. Motivational interviewing with problem drinkers. Behav Psychotherapy 1983; 11: 147-172.

28. Vasilaki El, Hosier SG, Cox WM. The efficacy of motivational interviewing as a brief intervention for excessive drinking: a meta-analytic review. Alcohol 2006; 41(3):
328-335.

29. Rubak S, Sandbaek A, Lauritzen T, Christensen B. Motivational interviewing: a systematic review and meta-analysis. Br J Gen Pract 2005; 55(513): 305-312.

30. Stein MD, Charuvastra A, Maksad J, Anderson BJ. A randomised trial of a brief alcohol intervention for needle exchangers (BRAINE). Addiction 2002; 97(6): 691-700.

31. Miller WR, Wilbourne PL. Mesa Grande: a methodological analysis of clinical trials of treatments for alcohol use disorders. Addiction 2002; 97(3): 265-277.

32. van Beek I, Dwyer R, Dore DG, Luo K, Kaldor JM. Infection with HIV and hepatitis $C$ virus among injecting drug users in a prevention setting: retrospective cohort study. BMJ 1998; 317: 433-437.

33. Anderson P, Baumberg B. Alcohol in Europe, London: Institute of Alcohol Studies; 2006.

34. Kelleher C, Nic Gabhainn S, Friel S et al. Survey of Lifestyle, Attitudes and Nutrition (SLÁN) and The Irish Health Behaviour in School-Aged Children Survey (HBSC), Galway: Centre for Health Promotion Studies, NUI, 2003.

35. Morgan K, McGee H, Watson D et al. SLÁN 2007: Survey of lifestyle, attitudes and nutrition in Ireland. Main Report. Dublin: Department of Health and Children, 2007

36. Cleary A, Nixon E, Fitzgerald M. Psychological health and well being among young Irish adults. Ir J Psych Med 2007; 24: 139-144.

Irish adults. Ir J Psych Med 2007; 24: 139-144.
37. Anderson RJ. Alcohol Aware Practice Pilot Study. Dublin. Irish College of General Practitioners, 2003

\section{VPST US -ก)}

The Irish Journal of

Psychological Medicine is Ireland's only peer reviewed clinical psychiatry journal. The Journal has been supporting original Irish psychiatric research for almost 25 years and through rigorous peer review has established itself as an independent and respected voice in psychiatry.

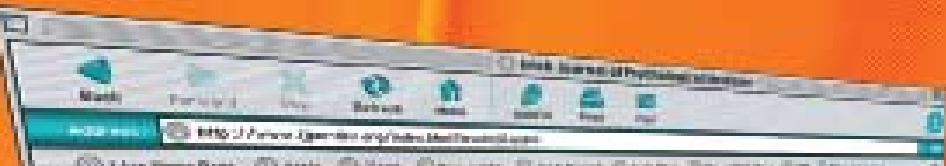

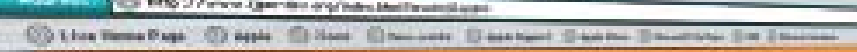

ip.1sh jothital or PSTCHOLOGICAL MEDTCINE

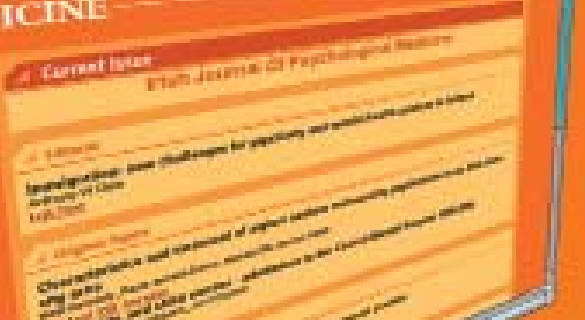

Main features of the site include:

- Fully searchable databese

- Past issues

- Useful links

- Guidelines for authors 